\title{
AVALIAÇÃO ECODINÂMICA DA BACIA HIDROGRÁFICA DO RIO PARAMOPAMA - SÃO CRISTÓVÃO/SERGIPE
}

\author{
Neise Mare de Souza Alves ${ }^{(a)}$, Débora Barbosa da Silva ${ }^{(b)}$, Helber Gomes Fortes ${ }^{(c)}$, Bruna \\ Leidiane Pereira Santana ${ }^{(d)}$
}

(a) Departamento de Geografia, Universidade Federal de Sergipe, neisemare@ gmail.com

(b) Departamento de Geografia, Universidade Federal de Sergipe, deborabarbs@ gmail.com

(c) Departamento de Geografia, Universidade Federal de Sergipe, hg_fortes@hotmail.com

(d) Departamento de Geografia, Universidade Federal de Sergipe, bruna.leydiane @ gmail.com

\section{EIXO: BACIAS HIDROGRÁFICAS E RECURSOS HÍDRICOS: ANÁLISE, PLANEJAMENTO E GESTÃO}

\begin{abstract}
Resumo
A bacia do rio Paramopama drena o antigo sítio onde se instalou inicialmente a capital de Sergipe. Na atualidade, ela apresenta diferentes tipos de uso e são visíveis os impactos ambientais sobre os recursos hídricos. Este trabalho tem por objetivo avaliar o estado das unidades de paisagem da bacia segundo a ecodinâmica de Tricart (1977), a partir de um diagnóstico morfodinâmico. Os procedimentos metodológicos foram: levantamento bibliográfico, análise do material cartográfico e trabalhos de campo. Foram identificadas seis unidades de paisagem: Topos sub-horizontais, Vertentes fracamente antropizadas, Vertentes antropizadas, Vertentes com áreas de solo exposto, Planície aluvial e Planície Fluviomarinha. Estas unidades foram enquadradas em uma das categorias ecodinâmicas obtidas: Meios Estáveis, Meios Relativamente Estáveis, Meios Intergrades e Meios Fortemente Instáveis. Elas estão condicionadas por um conjunto de processos morfodinâmicos regulados, principalmente, pelo clima e pelas ações antrópicas. O estudo constatou-se que na bacia do rio Paramopama predominam os Meios Intergrades.
\end{abstract}

Palavras chave: Avaliação ecodinâmica. Bacia do rio Paramopama. Recursos hídricos. Unidades de paisagem.

\section{Introdução}

A história da humanidade é marcada pelo uso dos recursos naturais disponíveis no meio ambiente, que sejam capazes de garantir a sobrevivência dos grupos sociais que se instalam naquela área. As técnicas evoluíram e a extração desses recursos foi paulatinamente crescendo, a ponto de, na atualidade, se falar em escassez ou ameaça de escassez de alguns deles, com destaque para a água. Assim, os estudos ambientais passaram a ser necessários para avaliar a capacidade de suporte dos recursos naturais. 
Nesta perspectiva, em meados do século XX, surgiram propostas teórico-metodológicas que passaram a focalizar os estudos do meio ambiente a partir da análise integrada, tendo por base os pressupostos da Teoria Geral dos Sistemas (BERTALANFFY, 1973).

No âmbito da Geografia, dentre as produções baseadas nos fundamentos dessa teoria, destacam-se as abordagens teórico-metodológicas dos geossistemas (SOTCHAVA, 1977; BERTRAND, 1972) e da Ecodinâmica (TRICART, 1977). A primeira proposta integra em sua análise os elementos naturais do meio ambiente e a ação antrópica, considerando a categoria paisagem. Por sua vez, a segunda propõe uma taxonomia que permite avaliar o estado das unidades de paisagem, de acordo com o balanço morfogênese-pedogênese, classificando-o de acordo com o grau de estabilidade ou instabilidade.

Assim, na ciência geográfica, os estudos ambientais passaram a empregar os princípios sistêmicos e a adotar a paisagem como categoria em suas análises. Este conceito foi resgatado Bertrand (1972) que o aplicou no modelo dos geossistemas. Para este autor, a paisagem é uma porção do espaço, resultante da interação dinâmica e instável de atributos físicos, biológicos e antrópicos, que interagem dialeticamente, uns sobre os outros, tornando-a um conjunto único e indissociável. Portanto, a paisagem se encontra em permanente evolução.

No Brasil, Christofoletti (1999) contribuiu afirmando que na Geografia, o conceito paisagem é fundamental, na medida em que permite compreender o espaço enquanto um sistema ambiental, físico e socioeconômico. Desse modo, a sua estrutura, funcionamento e dinâmica são definidos na interação dos elementos físicos, biogeográficos, sociais e econômicos.

Nos dias atuais, tanto os pressupostos geossistêmicos como os da ecodinâmica continuam sendo aplicados na análise geoambiental, principalmente, quando se objetiva realizar um diagnóstico, tal como se propõe neste estudo. Para compreensão da dinâmica de uma bacia hidrográfica se faz necessário analisar o ambiente onde ela está inserida, devendo ser analisado de modo integrado os aspectos físicos, sociais e econômicos, pois as humanas podem comprometer a qualidade e escassez dos recursos hídricos.

A bacia hidrográfica do rio Paramopama abrange uma área que abrigou, inicialmente, a capital do estado de Sergipe. Ela está situada totalmente no município de São Cristóvão. Este sistema hidrográfico drena a sede municipal atual, ou seja, uma área urbanizada. Assim, sua paisagem apresenta impactos de diferentes origens que compromete os recursos hídricos, no que se refere à conservação e à qualidade.

Assim, este artigo tem por objetivo avaliar o estado das unidades de paisagem da bacia segundo os fundamentos da ecodinâmica de Tricart (1977), a partir de um diagnóstico morfodinâmico, relacionando 
com o uso das terras. Os estudos poderão contribuir para subsidiar propostas de planejamento e gestão da bacia em análise.

\section{Materiais e métodos}

Este estudo se baseia na análise integrada da paisagem e desenvolveu-se apoiado nos princípios holísticossistêmicos da Teoria Geral dos Sistemas (BERTALANFFY, 1973), que entende sistema como algo definido na totalidade e na interdependência de seus componentes, a partir das trocas de energia e matéria estabelecidas entre eles.

Para estudos referentes a bacias hidrográficas, a aplicação dos princípios sistêmicos se revela adequada porque o sistema fluvial integra os componentes naturais e os da dinâmica social, representada pelo uso das terras e dos recursos hídricos, de diferentes formas.

Com base em alguns conceitos pode-se conceber bacia como uma unidade espacial delimitada topograficamente por interflúvios, drenada por uma rede canais de escoamento que confluem para um rio principal e na sequência para um exutório (CHRISTOFOLETTI, 1980; MACHADO E TORRES, 2012). Constata-se que a bacia hidrográfica apresenta uma hidrodinâmica que depende de fatores naturais. Assim, as intervenções antrópicas sobre um dos componentes físicos resultam em alterações que se refletem na totalidade da sua dinâmica.

Neste estudo foi aplicada a ecodinâmica, Tricart (1977). Nesta obra, o autor explicita os critérios para avaliação do estado da paisagem, com base na análise do balanço pedogênese/morfogênese. Assim, estabelece a classificação ecodinâmica inspirada na teoria da bioresistasia de Henry Erhart, identificando três tipos de meios: Estáveis, Intergrades e Fortemente Instáveis.

Os Meios Estáveis são caracterizados como aqueles em que os processos de formação do solo (pedogênese) prevalecem sobre os processos erosivos (morfogênese). Esse autor afirma, que "esta noção de estabilidade evolui lentamente, muitas vezes de maneira insidiosa, dificilmente perceptível. Os processos mecânicos atuam pouco e sempre de modo lento" (TRICART, 1977, p. 35), ou seja, a morfogênese não se manifesta de maneira evidente na paisagem.

Dentre os fatores que favorecem a estabilidade destacam-se:

[...] cobertura vegetal suficientemente fechada para opor um freio eficaz ao desencadeamento dos processos mecânicos da morfogênese; dissecação moderada, sem incisão violenta dos cursos d'agua, [...], e vertentes de lenta evolução; ausência de 
manifestações vulcânicas suscetíveis de desencadear paroxismos morfodinâmicos [...] (TRICART, 1977, p. 36).

A cobertura vegetal é um dos componentes mais importantes na paisagem, uma vez que protege o solo contra as ações mecânicas de processos morfogenéticos como o efeito splash, resultante do impacto das gotas de chuva sobre o solo exposto, o escoamento superficial e a erosão eólica.

Os Meios Intergrades são representados por aqueles que apresentam aspectos de transição, ou seja, refletem a "passagem gradual entre os meios estáveis e os meios instáveis" correspondendo a um contínuo. O que caracteriza esses meios é alternância permanente entre os processos que comandam a morfogênese e a pedogênese (TRICART, 1977, p. 47). Nessas condições, mudanças simples nos condicionantes ambientais, podem fazer a unidade de paisagem evoluir para condições de desequilíbrio. Assim, os meios intergrades podem ora se aproximar das características dos meios estáveis, ora dos meios instáveis.

Nos Meios Fortemente Instáveis verifica-se o predomínio da morfogênese sobre a pedogênese. Desse modo, os processos morfogênicos, que degradam a paisagem dominam a dinâmica do sistema natural condicionante. Assim, de modo geral, evidencia-se uma maior tendência à instabilidade e feições erosivas. São vários os fatores que determinam a ocorrência desse tipo de categoria. O autor referido insere desde os processos associados à geodinâmica interna, particularmente, por ação vulcânica, até as mudanças climáticas que determinam alterações na densidade, porte ou não existência de massa vegetal, além da ação antrópica.

A degradação antrópica da paisagem está quase sempre associada à necessidade de produção econômica. Os desmatamentos para implantação de cultivares, pastagens, atividade mineradora e residências deixam os solos expostos à erosão, favorecendo o desenvolvimento e/ou potencializando a ação dos processos morfodinâmicos.

\section{Materiais e métodos}

O desenvolvimento destes estudos requereu diferentes fases. O levantamento bibliográfico incluiu livros, artigos científicos, monografias, dissertações de mestrado e teses de doutorado, com ênfase nas propostas teórico-metodológicas que nortearão os estudos.

Por sua vez, o levantamento cartográfico foi pautado na fotointerpretação de aerofotos coloridas, escala 1: 25.000 da Base Cartográfica dos Municípios Litorâneos de Sergipe, da Secretaria de Estado do 


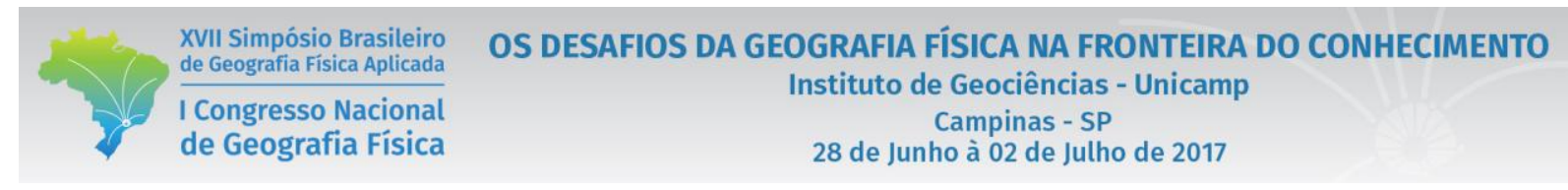

Planejamento de Sergipe - SEPLAN (2003); análise de mapas temáticos e textos do PROJETO RADAMBRASIL (BRASIL, 1983); folhas topográficas de Estância (SC. 24-Z-D-I), escala 1:100.000, da Superintendência de Desenvolvimento do Nordeste (SUDENE, 1974) e Aracaju ( SC. 24-Z-B-IV), escala 1:100.000 (SUDENE, 1974); texto e mapa de Geologia e Recursos Minerais do Estado de Sergipe, escala 1.250.000 (SANTOS et al., 1998). Na confecção do mapa morfodinâmico da área de estudo foram empregadas ferramentas do SIG (Sistema de Informação Geográfica) a partir do software ArcGIS 9.3.

Foram realizados trabalhos de campo para observação da organização da paisagem, das características das feições morfológicas e processos morfodinâmicos na área da bacia, além dos aspectos da ocupação e tipos de uso das terras. O contato com a população local, nesta etapa, permitiu a aquisição de informações sobre as atividades produtivas desenvolvidas.

\section{Resultados e discussão}

\subsection{Caracterização da área de estudo}

A bacia do rio Paramopama é uma sub-bacia do rio Vaza-Barris, com aproximadamente $13,2 \mathrm{Km}^{2}$ de extensão, situada no município de São Cristóvão, Sergipe (Figura 01). Embora apresente pequena área, ela constitui um importante recurso hídrico para a população e assegura o desenvolvimento de diferentes atividades produtivas, sobretudo no baixo curso.
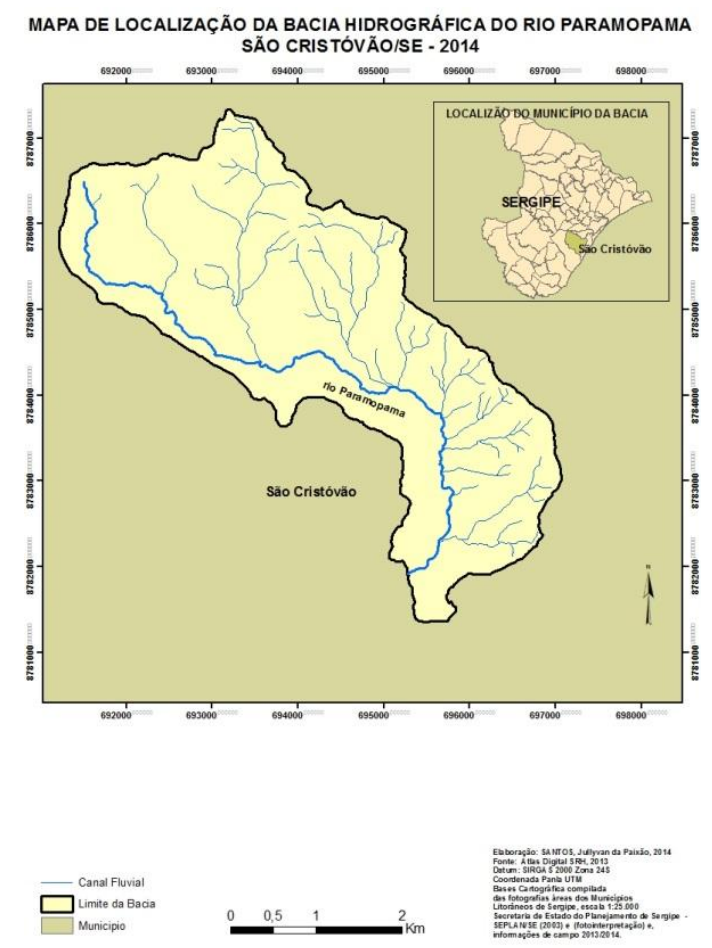
Figura 01 - Mapa de localização da bacia hidrográfica do rio Paramopama. São Cristóvão/SE

Fonte: Santos (2014)

Regionalmente, a bacia se encontra submetida ao clima Megatérmico Tropical Subúmido, com duas estações bem definidas, uma chuvosa, com precipitações concentradas no período outono-inverno e outra seca, entre os meses de dezembro e fevereiro. As médias pluviométricas anuais variam entre 1.000 e $1.400 \mathrm{~mm}$ e a temperatura média anual situa-se em torno de $25^{\circ} \mathrm{C}$, apresentando pequena amplitude térmica (FRANÇA E CRUZ, 2007, apud, SANTOS, 2007). As características da distribuição anual da pluviosidade constitui o elemento importante na condução dos processos morfogenéticos.

No contexto geológico, Santos et al., (1998) identifica na na área bacia do rio Paramopama as Formações Superficiais Continentais - representada pelo Grupo Barreiras, cujos sedimentos terrígenos correspondem a "arenitos finos e médios, siltitos e argilas variegadas com níveis caulinicos e conglomerados às vezes grosseiros, reunidos por cimento ferruginoso consistente; estratificação horizontal indistinta e incipiente" (BRASIL, 1983). Os Depósitos flúvio-lagunares compostos por areia e siltes argilosos e os Depósitos de mangues e pântanos atuais formados por materiais argilo-siltosos, ambos ricos em matéria orgânica (SANTOS, et al., 1998).

Geomorfologicamente, a área está inserida no Domínio Morfoestrutural - Depósitos Sedimentares, representado pelas Regiões - Piemontes Inumados e Planícies Litorâneas, as quais compreendem, respectivamente, as unidades geomorfológicas - Tabuleiros Costeiros e Planícies Deltaicas, Estuarinas e Praiais (BRASIL, 1983).

A unidade Planícies Deltaicas, Estuarinas e Praiais se caracterizada "por grupamentos de formas de origem marinha, fluviomarinha, lacustre e eólica, depositadas sob a influência das condições ambientais variáveis, que ocorreram durante o Quaternário" (BRASIL, 1983, p. 384). Na área de estudo ela corrresponde à Planície Fluviomarinha situada na foz do rio Paramopama, que deságua no ambiente estuarino do rio Vaza-Barris. (Figura 02).

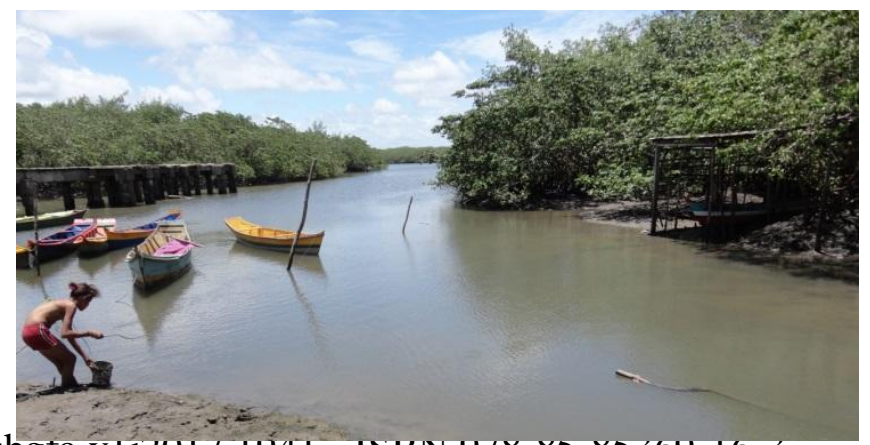


Figura 02 - Planície Fluviomarinha, com vegetação de Mangue. Baixo curso do rio Paramopama São Cristóvão/SE.

Fonte: Fortes (2014)

Por sua vez, os Tabuleiros Costeiros se caracterizam por topos planos ou sub-horizontais, bordos e vertentes. Os bordos são os elementos de maior gradiente de declividade e é onde se encontram as cabeceiras dos canais de drenagem. A dinâmica do escoamento fluvial disseca as vertentes. Consequentemente, no decorrer do tempo geológico, essa esculturação resultou em interflúvios tabulares estreitos, colinas e cristas que compõem a paisagem. Na atualidade, a ação dos processos morfogenéticos - escoamento superficial difuso e concentrado, rastejamento e deslizamento, produzem feições erosivas sulcos, ravinas e voçorocas.

Durante os trabalhos de campo foi possível observar que o Grupo Barreiras apresenta um nível conglomerático de cimentação ferruginosa que conserva a as feições tabuliformes dos topos.

Segundo Brasil (1983), a cobertura vegetal original corresponde à Floresta Estacional com manchas de Cerrado e às Formações Pioneiras de Influência Fluviomarinha. O primeiro conjunto florístico caracteriza a unidade Tabuleiros Costeiros, recobrindo os solos da classe ARGISSOLOS VERMELHOAMARELO Tb Distróficos, e, o segundo, é representada pela vegetação de Mangue, que coloniza os SOLOS INDISCRIMINADOS DE MANGUE, na Planície Fluviomarinha. Observa-se na área da bacia em análise, que a vegetação apresenta graus de antropização diferenciados. Destaque-se que a ação dos processos morfodinâmicos torna-se mais eficiente onde a vegetação está antropizada e se encontra áreas de solo exposto. A Planície Fluviomarinha apresenta forte grau de antropização em razão do corte da vegetação para instalação do centro comercial da sede municipal, de residências da população de menor poder econômico, e de viveiros da aquicultura, para criação de camarões e peixes.

O rio principal e seus afluentes drenam a área urbana do município de São Cristóvão. A rede hidrográfica encontra-se submetida a inúmeras intervenções antrópicas - construção de barramentos nos pequenos canais fluviais visando o aproveitamento hídrico, reduzindo o volume do débito e a velocidade do fluxo com repercussões no transporte da carga detrítica nos canais, despejo de dejetos domésticos sem tratamento, entre outros. Apesar dos impactos ambientais visíveis na rede de drenagem, as "bicas" 
instaladas no baixo curso do rio no Parque Governador João Alves Filho e na área da Biquinha do Jardim são exemplos da importância desses recursos hídricos para a população (Figura 03).

As margens do rio Paramopama, principalmente, no baixo curso soferam forte alteração, apresentando setores onde foram retificadas por obras de engenharia. A carga detrítica predominante no canal são areias de diferentes granulometrias e pequenos seixos. No Parque Governador João Alves Filho o canal possui entre $6 \mathrm{~m}$ e $7 \mathrm{~m}$ de largura. No alto curso, os vales apresentam-se encaixados e se alargam na direção da jusante, configurando a feição de vale em manjedoura.

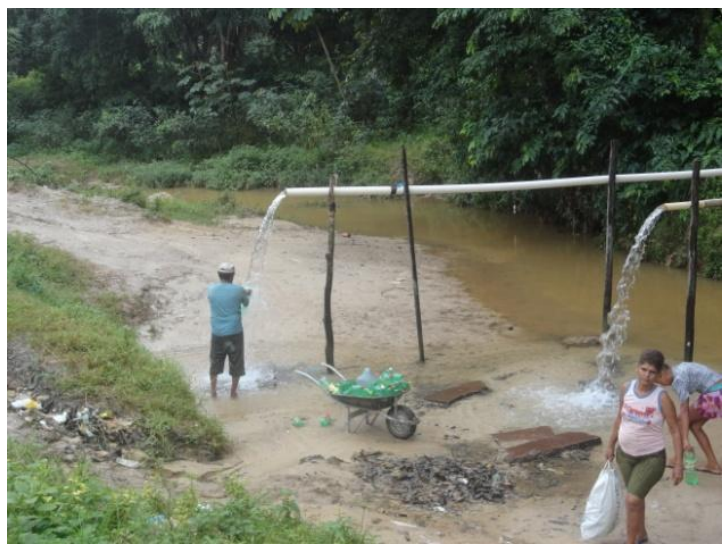

Figura 03 - Biquinha do Jardim, uso da água- baixo curso do rio Paramopama- São Cristóvão/SE.

Fonte: FORTES (2014).

No que se refere às ações antrópicas são visíveis na paisagem da bacia do rio Paramopama, como consequência da produção e organização do espaço geográfico. No alto curso, predomina o uso do solo com atividades ligadas à agropecuária, à extração mineral e propriedades com a finalidade de segunda residência. No baixo curso, a expansão do processo de urbanização propiciou um adensamento populacional e o uso do solo é destinado para diversas atividades: político-administrativa, comercial, residencial e aquicultura entre outros.

\subsection{Avaliação ecodinâmica da bacia do rio Paramopama}

A aplicação da proposta ecodinâmica (TRICART, 1977) na bacia do rio Paramopama, a partir análise integrada da paisagem, dos processos morfodinâmicos atuantes e do grau de antropização, possibilitou conhecer o diagnóstico morfodinâmico das seis unidades de paisagem - Topos sub-horizontais, Vertentes fracamente antropizadas, Vertentes antropizadas, Vertentes com áreas de solo exposto, Planície aluvial e Planície Fluviomarinha, que foram enquadradas em uma das cinco categorias ecodinâmicas - Meios Estáveis, Meios Relativamente Estáveis, Meios Intergrades ou Intermediários, Meios Relativamente 


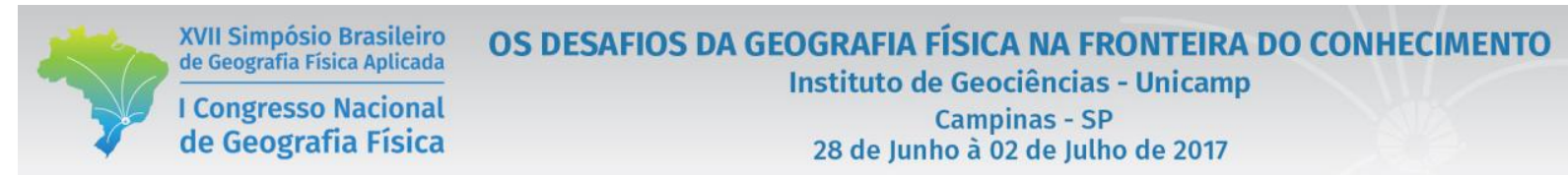

Instáveis e Meios Fortemente Instáveis. Elas encontram-se representadas cartograficamente no mapa morfodinâmico (Figura 04).

A Unidade Geomorfológica Tabuleiros Costeiros é composta por uma diversidade de feições morfológicas - Topos sub-horizontais, Vertentes fracamente antropizadas, Vertentes antropizadas, Vertentes com áreas de solo exposto e Planície aluvial (Figura 04).

\section{MORFODINÂMICA BACIA HIDROGRÁFICA DO RIO PARAMOPAMA SÃO CRISTÓVÃO - SERGIPE 2014}

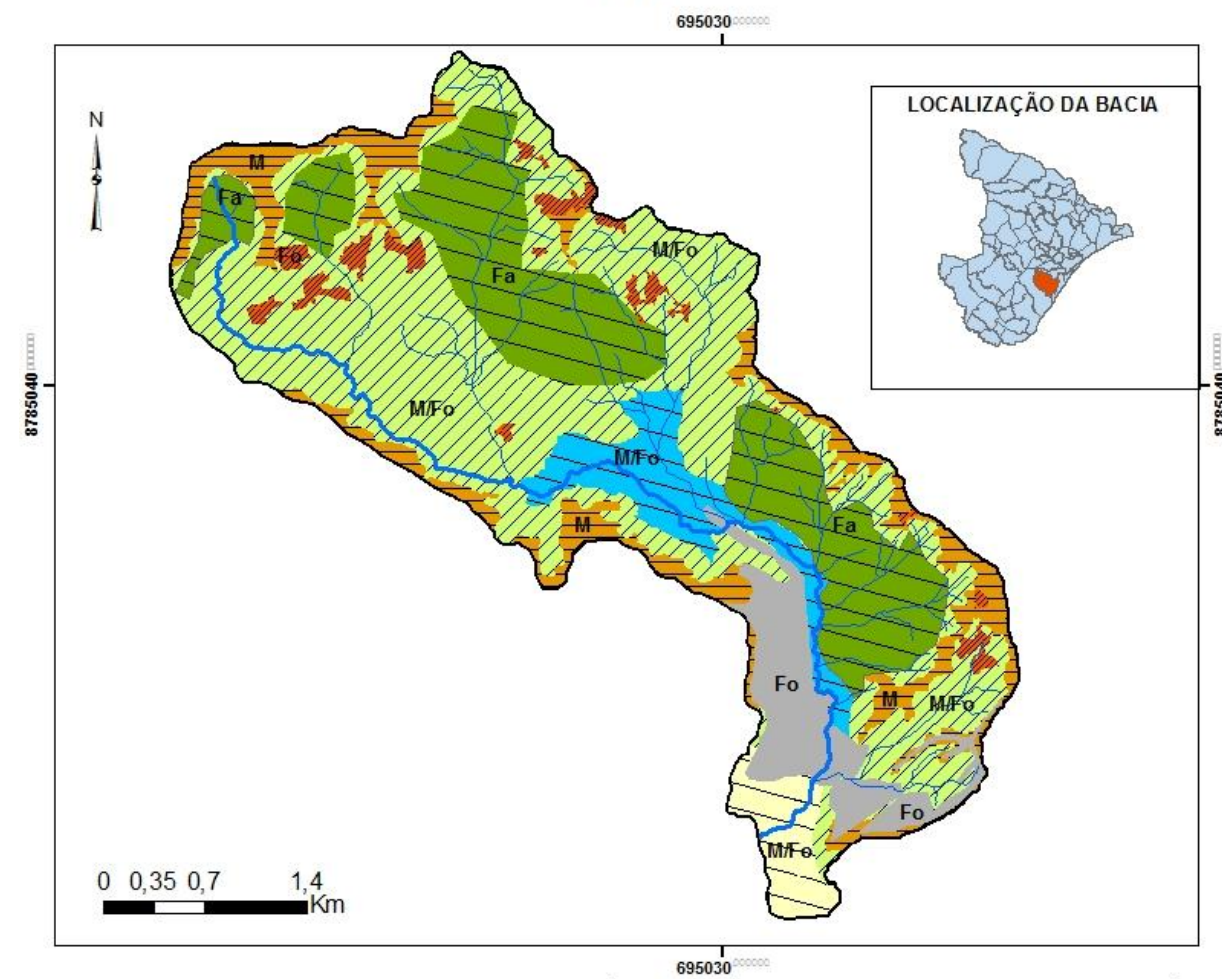

\begin{tabular}{l} 
I - MORFOLOGIA S \\
Topos sub-horizontais \\
Vertentes fracamente antropizadas \\
Vertentes antropizadas \\
Vertentes com áreas de solo exposto \\
Planície fluviomarinha \\
Planície aluvial \\
II - USO E OCUPAÇÃO DO SOLO \\
\hline Canal fluvial - pesca \\
Área urbanizada
\end{tabular}

DOI $-\underline{10 .}$

III - AVALIA ÇÃO ECODINÂ MICA

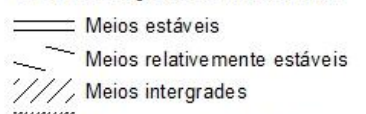

I , Meios intergrades

UIIIIII//, Meios fortemente instáveis
Fonte: Bsse cartográfica compilada das folhas Estância SC. 24Z-D-D e Aracaju SC. 24-Z-B-IV. ambas com es cala 1:100.000, da SEDENE (1974). Mapa de Geologia e Recursos Minerais do Es tado de Sergipe, escala 1: 250.000 (SAN TOS et al.., 1998), interpretaçäod aerofotos coloridas da Base Cartografica dos Municipios Litoranneos de Sergipe, escala 1:25.000, SEPLANTEC (2003) einformaçoes de campo 2013-2014, Atlas Digital SRH, 2013 Datum

Obs: Este maps é parte integrante do plano de trabalho DIAGNÓSTICO MORFODINÂMICO DA PAISAGEM DA BACIA HIDROGRAFICA DO RIOPARAMO PAMA, SÃO CRISTÓVÃO/SE,

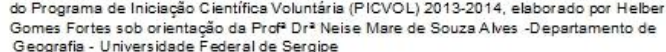


Figura 04 - Mapa morfodinâmico da bacia hidrográfica do rio Paramopama - São Cristóvão/SE.

Fonte: Fortes (2014)

Os Topos sub-horizontais são modelados onde se verifica declividade fraca ou nula, condição para a ação do processo de infiltração das águas pluviais sobre o solo. A percolação das águas provoca a intemperização da carapaça ferruginosa e o progresso da erosão regressiva das cabeceiras de drenagem com o desmantelamento do nível concrecionário. Considerando estas características e a atuação de processos morfodinâmicos lentos e de fraca intensidade, essa unidade de paisagem foi classificada como Meios Estáveis, verificando-se o predomínio da pedogênese sobre a morfogênese (Figura 04).

As Vertentes fracamente antropizadas são as que apresentam remanescentes da Floresta Estacional associada a manchas de Cerrado, estão nas áreas declivosas e de difícil acesso, situadas ao norte da bacia e ao longo da margem esquerda do rio principal (Figura 04). A cobertura vegetal em bom estado de conservação, atenua o efeito splash, pois as gotas da chuva não impactam diretamente o solo. Além disso, a matéria orgânica no solo contribui para aumentar a macroporosidade, reduzindo a erosão e favorecendo a infiltração. Apesar da declividade, a cobertura vegetal nestas unidades de paisagem limita a atuação dos processos erosivos e a perda de solo. Predominam os processos de infiltração, escoamento superficial difuso. Desse modo, foram classificadas como Meios Relativamente Estáveis.

As Vertentes antropizadas são predominantes na paisagem da bacia, tendo como características acentuado grau de declividade e o estado da Floresta Estacional revela certo grau antropização, pois parte da vegetação foi substituída por pastagem plantada (Figura 04). Embora se verifique essas condições, a cobertura vegetal ainda reduz o potencial erosivo do efeito splash e a ação de processos erosivos lineares. O estado da vegetação e as características da topografia são condicionantes favoráveis ao escoamento superficial concentrado, com formação de sulcos e ravinas, pontualmente. Nesta unidade de paisagem, os setores sem vegetação associado ao gradiente de declividade estão sujeitos aos movimentos de massa. Se o uso do solo for intensificado pode contribuir para que a morfogênese predomine sobre a pedogênese. Mas, se houver manejo adequado para as atividades produtivas, a pedogênese poderá ser favorecida. Logo, baseado nos critérios para avaliação ecodinâmica esta unidade foi inserida nos Meios intergrades ou intermediários. 
As Vertentes com áreas de solo exposto (Figura 04) evidenciam intensa ação antrópica relacionada à extração mineral dos sedimentos do Grupo Barreiras - areias e cascalhos - para uso na construção civil e pavimentação de estradas vicinais. Concentram-se no alto curso, nos setores noroeste e nordeste da bacia. A supressão da cobertura vegetal possibilitou a ação dominante do escoamento superficial concentrado, que produz feições erosivas lineares na paisagem, como sulcos e ravinas. Os deslizamentos ocorrem bnos setores íngremes e podem evoluir para voçorocas (Figuras 05). Os sedimentos são carreados para os leitos dos canais fluviais, assoreando-os. A forte antropização dessa unidade de paisagem $V$ permitiu classificála como Meios Fortemente Instáveis.

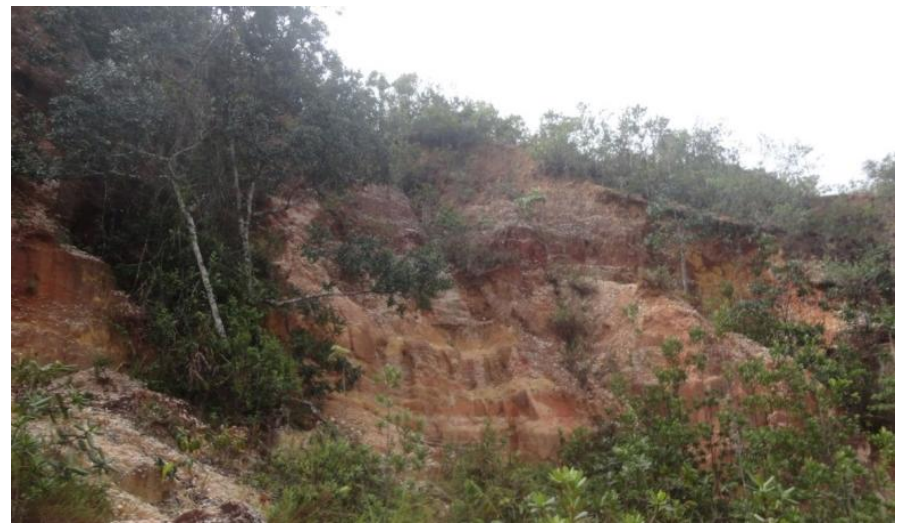

Figura 05 - Vertente antropizada, com cicatriz de deslizamento - Meios intergrades - Alto curso do rio Paramopama, São Cristóvão/SE Fonte: Fortes (2014)

A Planície aluvial é uma feição que compõe o vale e encontra maior expressão areal a partir do médio curso do rio Paramopama (Figura 04). Durante o período chuvoso, quando as águas do rio transbordam, os sedimentos são depositados em alguns setores, enquanto no baixo curso, ocorrem as inundações nas vias, residências e área comercial em razão da ocupação desrdenada da área. A topografia plana contribui para controlar a intensidade dos processos morfodinâmicos, sendo um fator propício à pedogênese. $\mathrm{O}$ tipo de uso determinou a supressão da cobertura vegetal nessa unidade de paisagem. Baseado no exposto e de acordo com os critérios ecodinâmicos, ela foi classificada como Meios Relativamente Estáveis.

A Planície fluviomarinha (Figura 04) corresponde a uma feição morfológica resultante da sedimentação fluvial e marinha na foz do rio Paramopama, que está sujeita às oscilações diárias das marés. A topografia plana facilitou a ocupação, encontrando-se implantadas principalmente as atividades aquícolas carcinicultura. A vegetação de Mangue foi suprimida em alguns setores para a instalação de viveiros, 


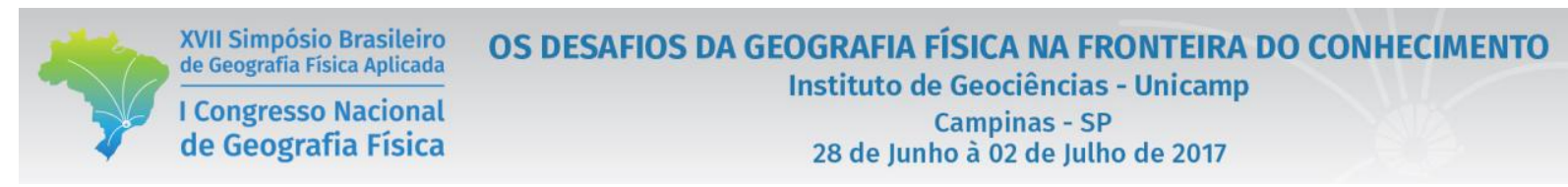

residências e equipamentos turísticos - bares e atracadouros. Esta unidade de paisagem foi classificada também como Meios Relativamente Estáveis.

A paisagem da bacia em análise possui no baixo curso do rio Paramopama uma área urbanizada que compreende o centro comercial e os núcleos residenciais no entorno da sede municipal (Figura 04). Esta área integra feições das duas unidades geomorfológicas - Tabuleiros Costeiros e Planície Fluviomarinha. O elevado grau de antropização descaracterizou as unidades de paisagem.

\section{Considerações finais}

A realização deste estudo com a aplicação das categorias da ecodinâmica permitiu alcançar o objetivo e compreender o funcionamento do sistema ambiental que domina na bacia hidrográfica do rio Paramopama. Portanto, os fundamentos teóricos e os procedimentos técnicos mostraram-se adequados.

A bacia hidrográfica reúne um conjunto de feições morfológicas, rede de canais fluviais, litologias, solos, vegetação e tipos de uso. As relações de interdependência dos fatores naturais e antrópicos no âmbito da bacia determinam a configuração de diferentes unidades de paisagem, cada uma com sua própria dinâmica, mas que compõem e definem a totalidade da paisagem regida pelo sistema ambiental. Estes estudos podem propiciar ações de planejamento dos recursos hídricos, no município.

\section{Bibliografia}

BERTALANFFY, L. Teoria geral dos sistemas. Petrópolis, Vozes, 1973.

BERTRAND, G. Paisagem e geografia física global: esboço metodológico. Caderno de Ciências da Terra, São Paulo, n. 13, p. 1-27, 1972.

BRASIL. Ministério das Minas e Energia. Projeto RADAMBRASIL: folha SC.24/25 Aracaju/Recife: geologia, geomorfologia, pedologia, vegetação, uso potencial da terra. Rio de Janeiro, 1983. 851 p. (Levantamento de Recursos Naturais,30).

CHRISTOFOLETTI, A. Geomorfologia. São Paulo, Edgard Blücher, 2ª edição, 1980.

. Modelagem de sistemas ambientais. São Paulo: Edgard Blucher, 1999. 233 p.

FORTES, H. G. Diagnóstico morfodinâmico da paisagem da bacia hidrográfica do rio Paramopama, São Cristóvão/SE. São Cristóvão: UFS, Pró-Reitoria de Pós-Graduação e Pesquisa, 2014. 41 f. Relatório final do Programa Institucional de Bolsas de Iniciação Científica.

MACHADO P. J. O. ; TORRES F. T. P. Introdução à Hidrogeografia. São Paulo - SP. 2012. 192 p.

SANTOS, R. A. et al.. Geologia e recursos minerais do estado de Sergipe: texto explicativo do mapa geológico do estado de Sergipe. Brasília: CPRM; Aracaju: CODISE, 1998. 
SANTOS, E. M. de O. Degradação ambiental na bacia do rio Paramopama no município de São Cristóvão em Sergipe (BRASIL). 2007. 60p. Monografia (Especialização)

SERGIPE. Secretaria do Planejamento e da Ciência e Tecnologia. Atlas digital sobre recursos hídricos de Sergipe. Aracaju, 2002. 1 CD-ROM.

Base cartográfica dos municípios litorâneos de Sergipe. Aracaju, 2003. Fotografias aéreas. Escala 1:25.000. 1 CD-ROM. Cobertura do município de Spão Cristóvão.

SOTCHAVA. V. B. O estudo do Geossistemas. Método em Questão, São Paulo, n. 16, 1977.

TRICART, J. Ecodinâmica. Rio de Janeiro: IBGE, 1977. 91 p. (Recursos naturais e meio ambiente, 1). 